\title{
Characteristics of Low Level Jets over Okinawa in the Baiu and post-Baiu Seasons Revealed by Wind Profiler Observations
}

\author{
Nga T. PHAM \\ Graduate School of Environmental Studies, Nagoya University, Nagoya, Japan \\ Kenji NAKAMURA, Fumie A. FURUZAWA \\ Hydrospheric and Atmospheric Research Center, Nagoya University, Nagoya, Japan \\ and \\ Shinsuke SATOH \\ National Institute of Information and Communications Technology, Tokyo, Japan \\ (Manuscript received 20 December 2007, in final form 13 June 2008)
}

\begin{abstract}
Hourly data from a 400-MHz Wind Profiler Radar (WPR) during the warm season months of three years are used to develop a climatology of the low level jet (LLJ) over Okinawa, a Japan subtropical island. Long-term observations of the wind with high temporal and vertical resolution allowed an investigation of the LLJ statistics. Characteristics of the LLJ are investigated in two subperiods: during the Baiu season over Okinawa Island and the post-Baiu season when the Baiu front has moved further north of Okinawa. The investigation result shows that stronger LLJs occur more frequently during the Baiu season, when heavy precipitation is mostly observed compared to the post-Baiu season. The appearance frequency of the maximum speed height of LLJs has a double peak structure in the vertical; lower and higher peaks appear around heights of $600 \mathrm{~m}$ and $1.3 \mathrm{~km}$, respectively. In the rain cases with daily rainfall equal and more than $1 \mathrm{~mm}$, another peak also appears around a height of $3 \mathrm{~km}$.

The frequency of LLJ occurrence exhibits a diurnal variation with the maximum in the nighttime and early morning, especially in the non-rain cases. The examination with upper-air sounding observations suggests that the nocturnal preference of LLJ occurrence is brought from the reduction of vertical mixing in the atmospheric boundary layer after sunset. Additional investigations of LLJs, using data from the WPR network of the Japan Meteorological Agency for three other stations surrounding Okinawa Island, provide more evidence for the role of the atmospheric boundary layer in generating the diurnal variation of LLJ occurrence.
\end{abstract}

\section{Introduction}

The low level jet (LLJ), the wind speed maxi-

Corresponding author: Nga T. Pham, Graduate School of Environmental Studies, Nagoya University, Furo-Cho, Chikusa-ku, Nagoya 464-8601, Japan E-mail: ptnga@satellite.hyarc.nagoya-u.ac.jp (C)2008, Meteorological Society of Japan mum that occurs in the lowest few kilometers of the troposphere, is frequently observed in many locations over the world including North and Central America, Europe, Africa, South America, Australia, and Asia (Stensrud 1996). One of the most predominant LLJs on the Earth is the Somalia LLJ flowing through Eastern Africa across the Indian Ocean to the coast of India 
(Findlater 1981). The LLJ over the Great Plains of the United State was reported early and widely in observational, theoretical and numerical studies (e.g., Blackadar 1957; Holton 1967; Bonner 1968). The prominent feature of the Great Plains LLJ is its strong diurnal variation, which was explained well by an inertial oscillation due to frictional drag inside the atmospheric boundary layer (ABL) (Blackadar 1957) and terrain induced effects (Holton 1967). A similar nocturnal LLJ was reported in the famous Wangara experiment (Australia), in which terrain-induced baroclinicity was also mentioned (Mahrt 1981). Over East Asia during the Baiu/Mei-Yu season, the presence of a southerly or southwesterly LLJ is one of the notable features of the Baiu front in association with heavy rainfall (e.g., Matsumoto et al. 1971; Matsumoto 1972). Generally, this LLJ appears along the south side of the front and has a remarkable ageostrophic component (e.g., Akiyama 1973b; Akiyama 1973c; Ninomiya and Murakami 1987).

The LLJ can form in response to a variety of influences, and numerous theories have been proposed to explain the mechanism for the development of the LLJ under different conditions and geographical locations. Regarding the driving force, Chen et al. (1994) classified the LLJ occurrence into two groups: the first is strongly related to ABL processes and the second is usually associated with synoptic or subsynoptic-scale weather systems. Most case studies of the LLJ around Japan focused on its formation and intensification, and its interaction with precipitation along the Baiu front (e.g., Matsumoto et al. 1971; Matsumoto 1972; Akiyama 1973a; Akiyama 1973b; Chou et al. 1990; Nagata and Ogura 1991; Kato 1998). It had been suggested that the enhancement of the LLJ is due to the vertical transport of horizontal momentum by convective activities. The formation of the LLJ to the south of the frontal zone through a convectively-induced circulation was discussed by Nagata and Ogura (1991) and Kato (1998) in their numerical studies. The LLJ mentioned in those studies belongs to the category of synoptic scale jets. Over the Kanto Plain of Japan, a nocturnal LLJ similar to the Great Plains LLJ was also reported by Harada (1981). The large diurnal variation of the Kanto Plain LLJ was suggested to be attributed not only to the frictional effect, but also to the diurnal variation of the local pressure field by thermal effects of the mountains (e.g., Harada 1981; Kimura 1983).

Climatological characteristics of the LLJ in the United States have been extensively studied (e.g., Bonner 1968; Mitchell et al. 1995; Arritt et al. 1997), but only a few have been studied in East Asia (e.g., Chen and Yu 1988; Chen et al. 2005). The recent work of Chen et al. (2005) on LLJ statistics was the most comprehensive for the Taiwan area by using conventional 12-hourly upperair soundings observed operationally and weather maps. However, the LLJ evolution cannot be adequately resolved with such 12-hourly observations (Bonner 1968). The previous lack of conventional observations makes it difficult to understand the detailed structure and short-term variation of the LLJs, and to examine the skill of numerical prediction models in simulating their development and evolution as well as related phenomena. This indicates the importance of a continuous, longterm record of highly resolved horizontal winds for characterizing LLJs over a specific region.

A wind profiler radar (WPR) gives continuous wind data with very high vertical and temporal resolution from near the surface to throughout the troposphere when conditions are favorable. This type of data provides a great advantage for observing phenomena such as the LLJ. Wind profiler network observations have been widely used for a case study as well as for a climatological study of the Great Plains LLJ (e.g., Arritt et al. 1997; Mitchell et al. 1995). Mitchell et al. (1995) compared their occurrence frequency of the LLJ with the results of Bonner (1968), and they implied that conventional 12-hourly upper-air sounding observations fail to detect many LLJ events and result in a bias of the LLJ evolution during their strong phase. However, it should be noted that WPRs sometime make erroneous observations caused by various contaminations, such as birds, insects, or any noisy environments (Merritt 1995).

Undoubtedly, long-term wind observations of a single WPR even at a single site will be advantageous for investigating finer structures and variations of the LLJ. In this paper, we use data from three years of $400-\mathrm{MHz}$ WPR observations for a first-time study of characteristics of the boundary layer wind structure and the associated LLJ over Okinawa Island (Fig. 1), which is one of the regions affected by the Asian southwest monsoon and is considered important for the formative stage of the Baiu season over Japan. Therefore, 
the first objective in this study is to analytically study the frequency of LLJ occurrence, its vertical structure, and its temporal evolution. It should be emphasized that the LLJ in our climatological analysis is different from the LLJ that occurred principally at the $800-600 \mathrm{hPa}$ levels in most previous studies around Japan (e.g., Matsumoto 1972; Akiyama 1973b; Kato 1998). Our second objective is to examine whether the LLJ over Okinawa during the southwesterly monsoon season has a diurnal signature similar to that over the Kanto Plain region, where the mountains in central Japan could generate mechanical and thermal effects for the formation and variation of the LLJ (Kimura and Arakawa 1983). Harada (1981) prophesied that the nocturnal LLJ may also be found in other regions of Japan. Our analysis is presented in a descriptive manner based on observational data. However, the formation mechanism of the LLJ itself is not the concern of this study, although the discussion is further connected with possible mechanisms of involved phenomena.

The paper is arranged as follows: after this introduction, Section 2 briefly describes the WPR specifications and the availability of profiler data for observing the LLJ over this site. Section 3 presents the analysis results. Characteristics of the LLJ are separated into two subperiods: during the Baiu season over Okinawa Island and the post-Baiu season when the Baiu front has moved further north of Okinawa. These subperiods apparently exhibit rainy and fair weather conditions for this island. A comparison between them helps to make clearer a relationship between the LLJ and precipitation. In Section 4, possible influences on the diurnal variation of the LLJ are discussed. Additional results from the WPR network data of the Japan Meteorological Agency (JMA) are also presented to compare with results of Okinawa Island observations. The final section is the summary and conclusions.

\section{Availability of profiler data for observ- ing the LLJ}

The $400-\mathrm{MHz}$ WPR installed at the Ogimi site $\left(26^{\circ} 40^{\prime} \mathrm{N}, 128^{\circ} 09^{\prime} \mathrm{E}, 225 \mathrm{~m}\right.$ above mean sea level (MSL), see Fig. 1), belonging to the Okinawa Subtropical Environment Remote-Sensing Center of the National Institute of Information and Communications Technology (NICT) of Japan, has been in continuous operation for several years. It has two operating height modes with vertical

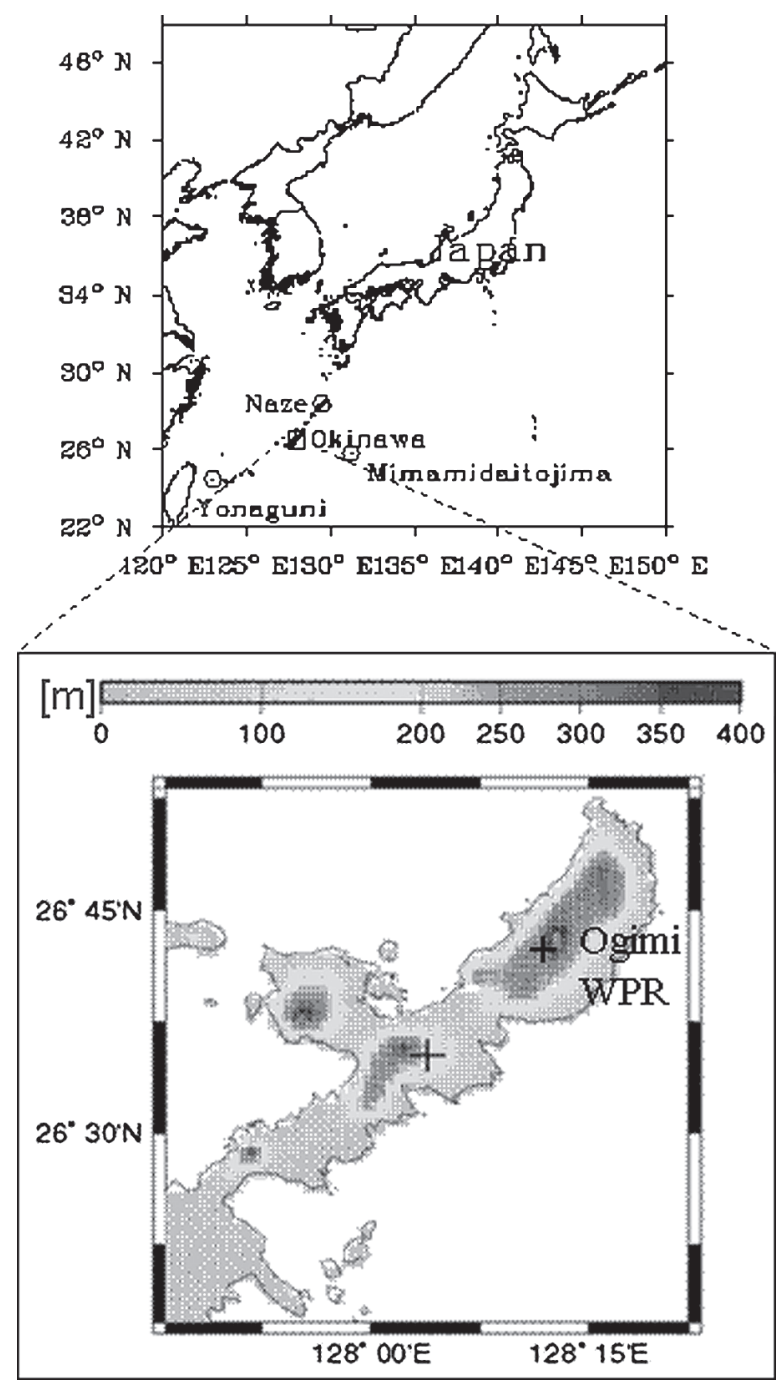

Fig. 1. Japan area map and locations of the JMA's three WPR stations (upper panel), and Okinawa Island topography and location of the Ogimi wind profiler site (bottom).

extension to $7.5 \mathrm{~km}$ and $18 \mathrm{~km}$, corresponding to vertical resolutions of $100 \mathrm{~m}$ and $150 \mathrm{~m}$ starting from the heights of $300 \mathrm{~m}$ and $400 \mathrm{~m}$ above ground level (AGL). Every mode completes an observational cycle made up of 5 beam sequences ( 1 zenith and 4 oblique beams at 11 degrees from zenith) in about 80 seconds. Details of design parameters and specifications of this WPR were described in Adachi et al. (2001). In this study, with a necessity of higher vertical resolution for finer structure of the LLJ, we use the low height mode 
data.

Following the common practice, the horizontal winds estimated from instantaneous observations are combined into 30-min averaged profiles. This averaging is used to obtain more reliable observations and to eliminate higher frequency fluctuations (Arritt et al. 1997). Before averaging, data quality control has been applied using the statistical window technique proposed by Angevine et al. (1993). Following this approach, three spectral parameters, including the signal to noise ratio (SNR), the Doppler velocity, and the width of Doppler Spectra from wind profiler data are discarded when they are outside of statistical limits. The data are divided into one-hour segments, and the statistical window is applied for every range gate. Then, 30-min averaged data could be constructed when at least 3 out of 10 profiles during this period survived the filtering procedure.

In our attempt to investigate a local climatology of the LLJ, first we checked the sufficiency of the data from the Ogimi profiler by their availability and quality, characterized by a missing rate. This is the ratio of the number of missing profiles to the total number of usable profiles. We applied this ratio only to $30-\mathrm{min}$ averaged profiles. The Ogimi profiler began routine operation in May 2003, but there were numerous missing data during this year. At the time we started this study, data were continuously available for the period from 2004 through 2006. During these three years, the dataset was more complete for the summer season, while there were long missing periods in winter from September 2004 to April 2005, and December 2006 to March 2007 because of system failures. Data from twelve continuous months from May 2005 to April 2006 and three summer months (May-July) of three years (2004 -2006) are used for this study with the focus on the southwesterly monsoon. Although a threeyear period of wind profiler data is not so long for climatological analyses, it is comparable with the data duration of similar studies using WPRs (e.g., Mitchell et al. 1995; Arritt et al. 1997). Notably, the fine vertical and temporal resolutions of the data are useful for studying detailed characteristics of LLJs.

While the occurrence of missing profiles was quite low during the study period, individual data points within a single profile were relatively missing. To quantify the occurrence of missing profiles, the missing ratio is calculated for each range gate at every 30-min period of averaged data by dividing missing data gates discarded after filtering by the total usable profiles. This ratio counts missing data from any specific range, which are not sufficiently robust to provide a high quality consensus 30-min averaged wind measurement. Typically, this means that there were insufficient strong return signals to the profiler receiver and/ or signals were rejected because of consensus averaging. On clear days, most return signals come from turbulence in the atmosphere, and at higher altitudes the missing ratio is higher because of long distance and less turbulence. A time-height cross section of missing rate for three month periods of three years data shows the rate of $10 \%$ below a $4-\mathrm{km}$ height, reaching up to over $30 \%$ above a 5-km height. Moreover, measurements from the two lowest ranges are missing at the highest rate (Fig. 2). Unavailability of data below a 500-m height makes it difficult to correctly detect LLJs there. To overcome this disadvantage of the wind profiler, in some other studies Doppler lidars or sodars were proposed as alternatives (Banta et al. 2002). Unfortunately, in our study those alternative data are not available except for surface observations. Figure 3 shows the total monthly missing rates from May 2005 to April 2006. The data captured during summer months, which are of the most interest to this study, are much improved with a missing rate of around $20 \%$, compared with $35-40 \%$ during the winter season.

\section{Low-level jet characteristics}

\subsection{Frequency of the LLJ}

The most commonly used criteria for identifying the LLJ in the United States follow the early work of Bonner (1968). In general, two basic criteria are set up. The first is a threshold value for the maximum wind and the second is a fall-off value from the wind speed maxima upward to the next wind speed minimum or to a $3-\mathrm{km}$ level. A bigger fall-off value is required for stronger maximum wind speed. Some modifications of the criteria had been applied in later works of Mitchell et al. (1995) and Banta et al. (2002) to fit the nocturnal LLJ. For the Asia region, through several works of Chen and others (e.g., Chen and Yu 1988; Chen et al. 2005) the criteria of the LLJ only over Taiwan had been specified. That includes requirements on the maximum wind speed, the restriction of LLJ height and wind direction, and 


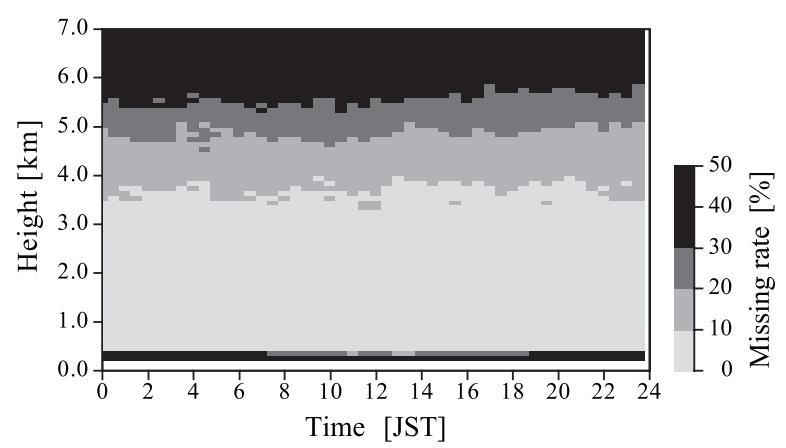

Fig. 2. Time-height cross section of data missing rate, depicted from the Ogimi profiler for three months of the 3-year period (Height is AGL).

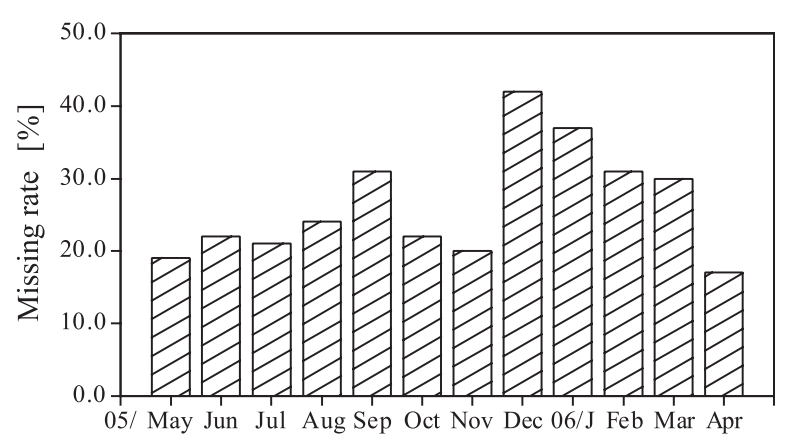

Fig. 3. Monthly variation in total data missing rates from May 2005 to April 2006.

horizontal and vertical shears. Chen et al. (2005) tested different values of vertical shear with the distribution of LLJ occurrence and chose a magnitude of $1 \times 10^{-3} \mathrm{~s}^{-1}$ vertical shear in their study. This threshold is somewhat smaller than Bonner's criteria.

In this study, we apply two sets of criteria for the LLJ detection. The stronger criteria require the maximum wind speed equal to or more than $12 \mathrm{~m} \mathrm{~s}^{-1}$ and the reduction of wind speed by at least $6 \mathrm{~m} \mathrm{~s}^{-1}$ from the height of wind maximum to that of wind minimum below $3 \mathrm{~km}$ or to 3 $\mathrm{km}$ when no minimum is found, and the weaker criteria require the maximum speed of $10 \mathrm{~m} \mathrm{~s}^{-1}$ and the reduction of $3 \mathrm{~m} \mathrm{~s}^{-1}$. The weaker criteria provide a larger number of LLJ samples and higher statistical significance to the climatology. These criteria are used for a one year period (May 2005 to April 2006) to examine seasonal changes of the LLJ. The LLJ with wind direction ranging

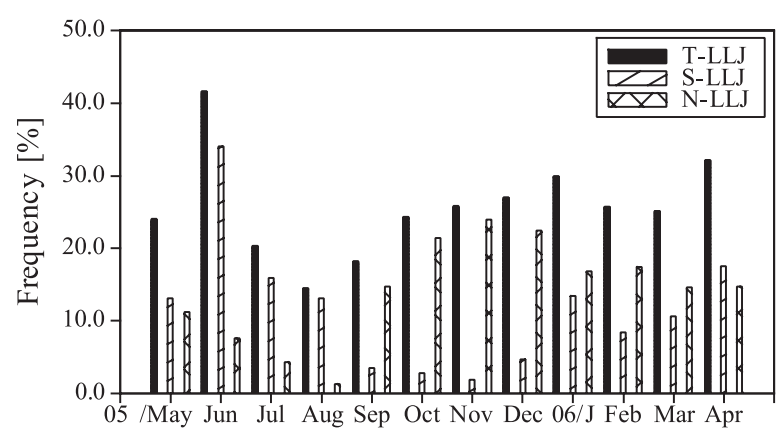

Fig. 4. Monthly distributions of frequency of total (T-LLJ), northerly (N-LLJ), and southerly (S-LLJ) LLJs from May 2005 to April 2006.

from 90 to 270 degrees is defined as southerly LLJ, the northerly LLJ is restricted to the wind direction from 0 to 90 degrees or from 270 to 360 degrees, and LLJs of all directions are counted for the total. The monthly distributions of total (TLLJ), southerly (S-LLJ), and northerly LLJ (N-LLJ) occurrence (Fig. 4) indicate that the LLJ occurs equally around the year, but southerly LLJs are typically confined to the summer season (from April to August) of prevailing southerly winds, while northerly LLJs are dominant mostly from September to December. The large-scale environment of the southerly LLJ in summer is significantly different from that of the northerly LLJ in winter. The southwesterly LLJ in summer appears in the southwesterly East Asia summer monsoon along the northwestern rim of the North Pacific subtropical anticyclone, whereas the northerly LLJ in winter appears in the northeasterly East Asia winter monsoon along the southeastern rim of the anticyclone over the cold East Asia continent. The LLJ occurs with the lowest frequency in transition months August and September of this year. The frequency of LLJ occurrence in April of 2006 is relatively higher than that in two previous months of 2006 and May of 2005. Data in April of 2004 and 2005 are not available for checking the consistency of this sudden increase. For our interest, we concentrate on the period of predominating southerly LLJs, which is considered one of the important features of the Baiu front in association with heavy precipitation over East Asia.

A close relationship between heavy precipitation and the wind speed of the LLJ in the Baiu system had been found in several studies. For 
example, a statistical study of Matsumoto (1973) showed that the strong Baiu LLJ over Kyusyu Island is highly correlated with intense precipitation. The analysis on mechanisms of the relationship between the LLJ and heavy rainfall is not addressed here, but characteristics of the LLJ under different conditions (rain vs. no rain) are examined and compared. For that purpose, in addition to WPR data, we collect rainfall data from a collocated automatic weather station (AWS) during the studied period. The rain gauge is the tipping bucket type, which records rain amounts every 1 minute at $0.5 \mathrm{~mm}$ minimum setting. A day with total rainfall accumulation of equal to or greater than $1 \mathrm{~mm}$ is defined as a rainy day. Four rainy days due to typhoon activities are excluded from the dataset. It is well known that the rainy season around Japan is mostly related to convective activities over the Baiu frontal zone. Climatologically, the Baiu over the Okinawa Islands and the other Japan islands lasts from early May to midJune and from mid-June to mid-July, respectively (Ninomiya and Akiyama 1992). An alternative approach is to divide three month periods into the Baiu and the post-Baiu subperiods. The former is when the Baiu front is confined to the Okinawa Islands and the latter is when the Baiu front has shifted northward to the other Japan islands. For this type of separation, we simply use dates proclaimed in annual Baiu season climate reports of the Tokyo Climate Center, the JMA. According to these reports, the Baiu period in the Okinawa Islands was from 8 May to 23 June for 2004, from 2 May to 27 June for 2005, and from 14 May to 20 June for 2006. After the Baiu ending dates, the post-Baiu subperiod is assumed to start and last until the end of July.

The predominant LLJ in the southwesterly flow (180-270 degrees) along the northwestern rim of the Pacific subtropical high south of the Baiu front has an important role in transporting water vapor to be condensed into precipitation over the Baiu frontal zone (Akiyama 1973c). The following analysis concentrates on this southwesterly LLJ. The variation of the 10-day frequency of the southwesterly LLJ, which is defined as the fraction of the number of LLJ profiles from total usable profiles in every 10 days during the three month period of three years, is displayed in Fig. 5 . It shows a higher frequency of LLJ occurrence starting from June and reaching the maximum of nearly $30 \%$ in the period of June $11-20$. It is

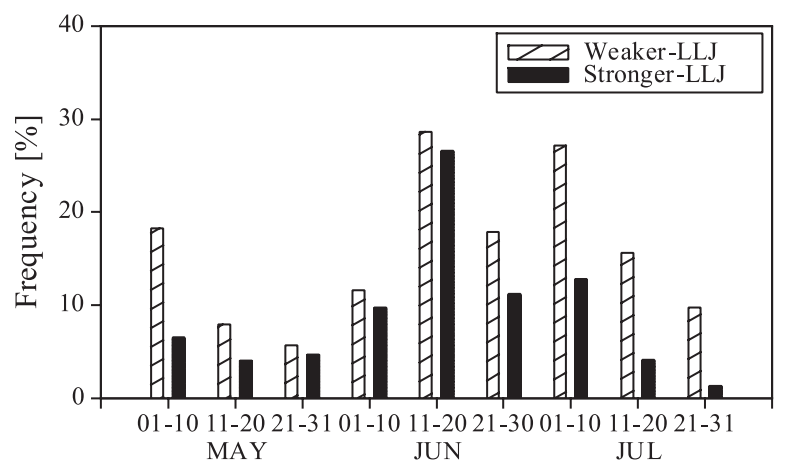

Fig. 5. Frequency variation of southwesterly LLJs for every 10 days from $1-10$ May to 21-31 July for the 3-year record.

noticed that the frequency in the period of June 21-30 becomes slightly lower before the period with the higher frequency (July 01-10). However, the difference in the frequency of stronger LLJ occurrence between two periods of June 21 -30 and July $01-10$ is not significant. A notable increase in the frequency of weaker LLJ occurrence is similarly found at the beginning period of the Baiu season (May 01-10). It is possible that $\mathrm{ABL}$ effects are enhanced before and after the Baiu season leading to the rise of the weaker LLJ. The stronger and weaker LLJs occur with the comparable frequency in the period of June 1 -20 . The frequency of stronger LLJ occurrence decreases quickly and becomes much smaller compared with that of weaker LLJ after July 10. This suggests that the stronger LLJ occurs more frequently during the later half of the Okinawa Baiu season, when convective activities over the Baiu frontal zone are usually the most intense over the Okinawa Islands and heavy precipitation is frequently observed there.

Next, we define the hourly frequency of LLJ occurrence as the percentage of detected LLJs at a given hour to the total profiles at that hour. Figure 6 shows the diurnal variation of weaker LLJ occurrence frequency for the three month period of three years (Fig. 6a), the Baiu subperiod (Fig. $6 \mathrm{~b}$ ), and the post-Baiu subperiod (Fig. 6c). In general, the higher frequency is found in the nighttime and early morning than in the daytime, and the early morning preference is more pronounced in the post-Baiu subperiod. The diurnal variation of stronger LLJ occurrence frequency shows the similar feature (not shown). However, the total 
(a)

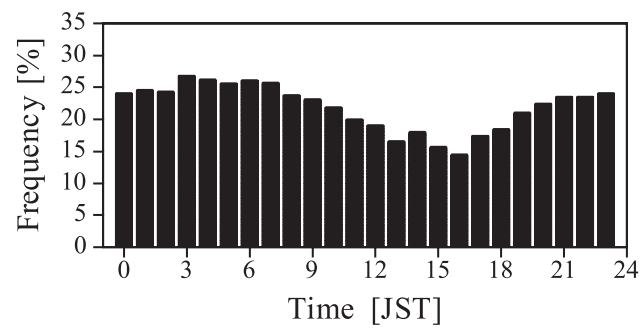

(b)

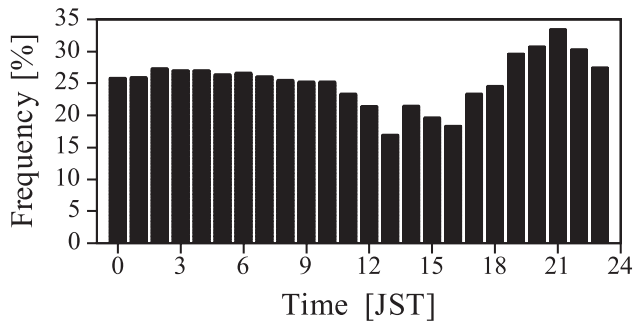

(c)

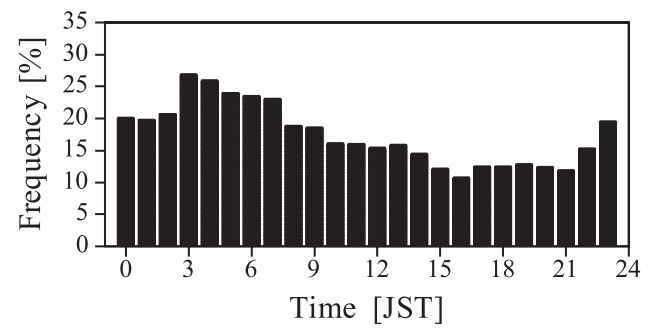

Fig. 6. Diurnal variations of the frequency of weaker LLJ occurrence for the (a) total, (b) Baiu, and (c) post-Baiu season from three months of the 3-year record.

frequency of stronger LLJ occurrence is reduced in the post-Baiu subperiod and the diurnal variation becomes unclear due to the small number of samples. The frequency distribution separated by month (not shown) reveals that the stronger LLJ occurs with the higher frequency in June than in May and July. This is consistent with a higher frequency of stronger LLJ occurrence during June 11-20 (Fig. 5). It is also interesting to note that a phase shift occurs in the time of the frequency peak. That is, the maximum frequency of LLJ occurrence is found before midnight in the Baiu subperiod (Fig. 6b), but in the morning in the post-Baiu subperiod (Fig. 6c). Compared with the diurnal variation of the LLJ occurrence frequency in the United States documented in Bonner (1968) and Mitchell et al. (1995), the amplitude of the variation over Okinawa is weaker. For example, for the stronger LLJ estimated by the similar criteria, both Mitchell et al. (1995) and Arritt et al. (1997) reported the nocturnal frequency of LLJ occurrence three or four times bigger than that in the daytime. In our statistics, the maximum occurrence frequency of about $20-25 \%$ is found in the nighttime and early morning compared with the minimum value of near $10-15 \%$ in the daytime, though it is for the weaker LLJ.

The difference between the Baiu and the post-
Baiu subperiods also appears in the distribution of LLJ's wind direction at the height with the wind speed maximum (Fig. 7). In the Baiu subperiod, the LLJ mostly has a southwesterly direction, while in the post-Baiu subperiod its wind direction changes to the southeasterly. This distribution of weaker LLJ's direction is generally in agreement with the change of the large-scale pressure pattern over the western Pacific and East Asia. Figure 8 shows the averaged geopotential height and horizontal wind at a $850-\mathrm{hPa}$ level, depicted from JMA meso-analysis data of 2005 for the Baiu period and post-Baiu subperiods around the Japan islands. The subtropical high extends more westward to the eastern coast of China in the post-Baiu subperiod. Compared to the Baiu subperiod the Okinawa Islands become covered by the western part of the subtropical high, where the wind changes more southerly in the post-Baiu subperiod. The dominant southwesterly LLJ during the Baiu season has been understood as the primary condition for the formation of the Baiu front. The advection of warm-moist air by the southwesterly LLJ causes frontogenesis, enhancement of convective instability, and strong moisture convergence (Ninomiya and Akiyama 1992). 
(a)

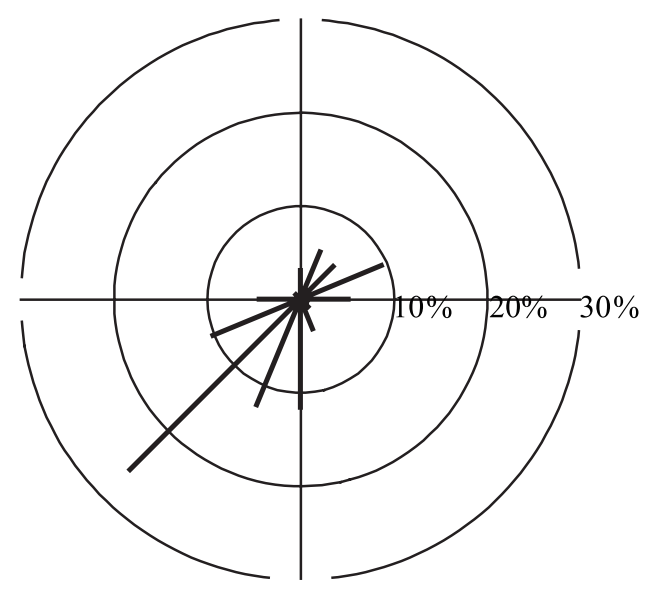

(b)

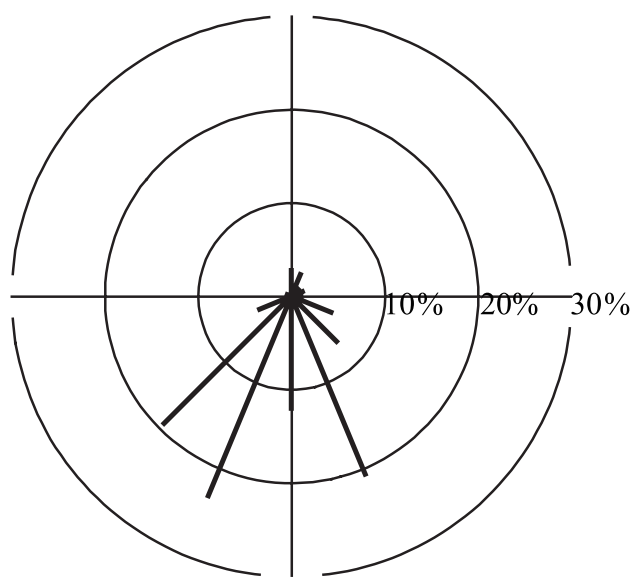

Fig. 7. Frequency distributions of weaker LLJ's direction for the (a) Baiu and (b) post-Baiu periods from three months of the 3-year record.

(a)

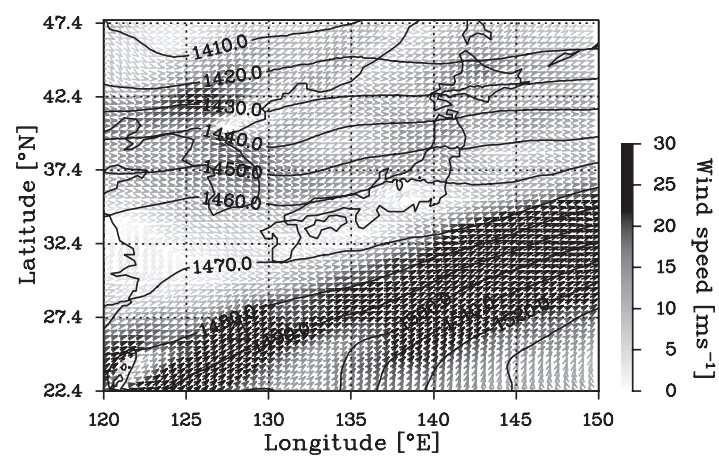

(b)

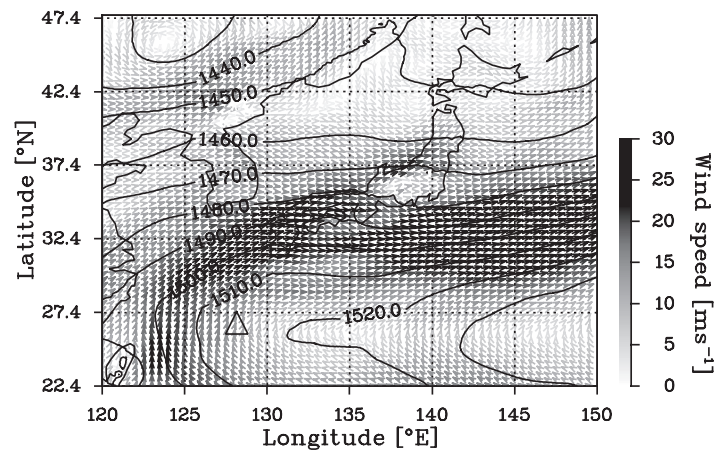

Fig. 8. Averaged geopotential height and horizontal wind field at a 850-hPa level for the (a) Baiu and (b) post-Baiu periods from JMA's meso-analysis data of 2005 (the triangle symbol is the location of Okinawa).

\subsection{Vertical structure}

The appearance frequency of the height with the wind speed maximum of LLJs for three month periods of three years, separated into the rain and non-rain cases, is shown in Fig. 9. The appearance frequency has a double peak structure in the vertical. The first peak is found at a 500-700 m (AGL) height range, and the second at an $1100-1300 \mathrm{~m}$ height range. A similar double peak structure was also noticed in the LLJ over the Taiwan area in the recent work of Chen et al. (2005). Using 10 years data of conventional upperair soundings and weather maps, they found two peaks correspondingly at $900-925 \mathrm{hPa}$ and $825-$ $850 \mathrm{hPa}$ levels. The higher peak was more sensitive to the wind shear threshold above the wind maximum, while the lower peak was corresponding to the strong wind shear. Based on that structure, Chen et al. (2005) suggested distinctly different mechanisms responsible for the formation of LLJs with the lower and higher wind maxima. The rain cases in the present study (Fig. 9b) have a more pronounced second peak at a higher level than the non-rain cases (Fig. 9c).

Figure 10 presents the diurnal variation of horizontal wind, averaged for cases with and without 
(a)

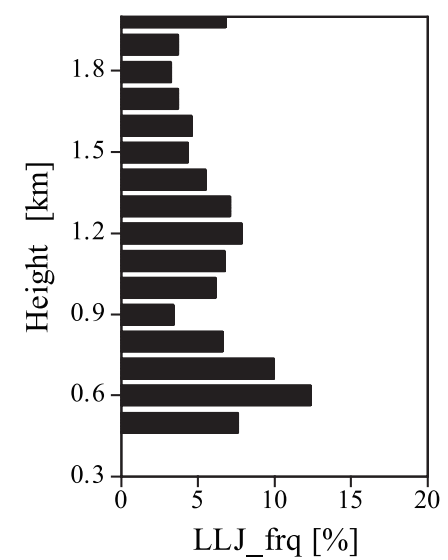

(b)

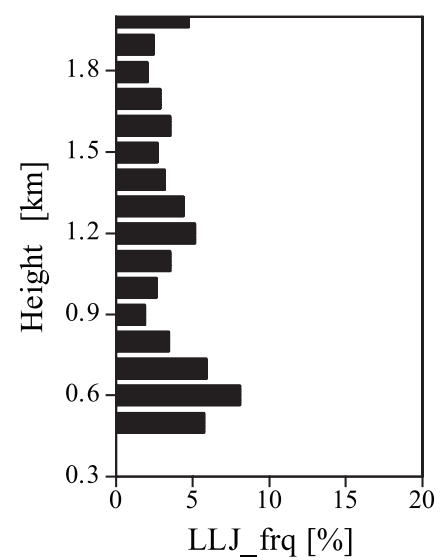

(c)

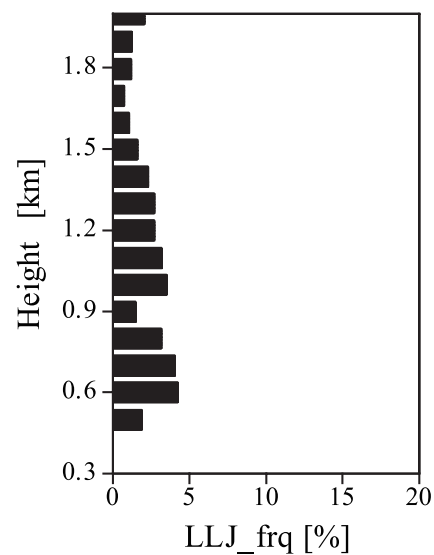

Fig. 9. Occurrence frequency of the heights of wind speed maxima for the (a) total, (b) rain and (c) non-rain periods from three months data of the 3-year record.

(a)
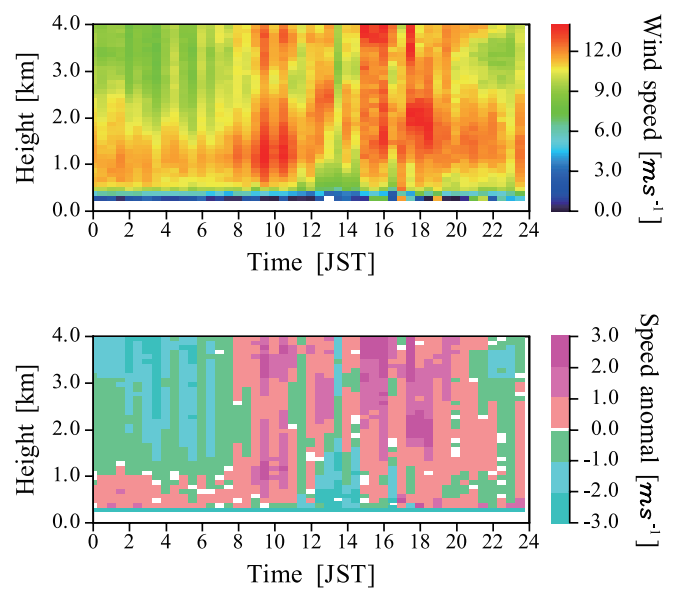

(b)
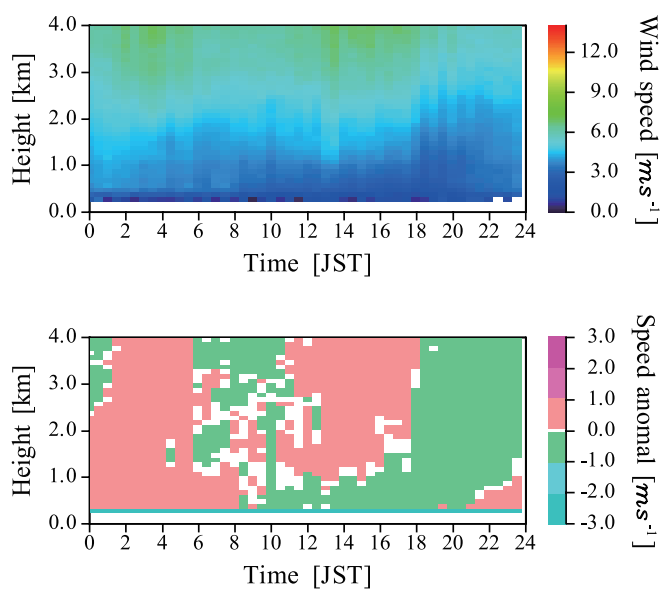

Fig. 10. Diurnal variations of the mean wind profiles as composited for (a) LLJ soundings and (b) nonLLJ soundings from three months of the 3-year record (at both: top-absolute wind speed, bottomwind speed anomaly).

LLJs during three months of three years data. Absolute wind speeds and their anomalies are shown in the upper and lower panels, respectively. The wind speed anomalies are constructed by subtracting the mean value at every level from wind speed at each hour. The mean jet wind (Fig. 10a) shows a significant enhancement of wind speed up to greater than $12 \mathrm{~m} \mathrm{~s}^{-1}$ below a height of 2 $\mathrm{km}$ until 08 Japan standard time (JST $=\mathrm{UTC}+9$ hours), and this enhancement extends upward be- tween 10-14 JST. The stronger wind shear above the level with the maximum wind speed is found in the nighttime. The procedure of averaging individual profiles having wind maxima at different heights and different numbers of profiles at a specific time results in the reduction of the maximum wind speed in mean profiles. In the lower panel of Fig. 10a, a positive anomaly is confined below a height of $1 \mathrm{~km}$ in the nighttime and early morning (00-08 JST), but it rises to higher levels 
in the daytime while a negative anomaly fills in lower levels. In contrast, the mean wind of nonLLJ profiles in Fig. 10b does not indicate a significant diurnal enhancement of wind speed in the lower troposphere. The wind speed strengthens in almost the whole layer below a $4-\mathrm{km}$ height in the nighttime and early morning, because the positive anomaly is found there. After sunrise, the wind below a height of $1 \mathrm{~km}$ begins to decelerate due to the increase of boundary layer mixing. On the other hand, the positive anomaly of wind speed shifts to higher levels with time in the morning.

We also construct the mean wind of LLJ profiles separately for the rain and non-rain cases as shown in Fig. 11. The mean maximum jet speed in the rain cases is stronger than in the non-rain cases. This result is consistent with that in the cases with the LLJ (Fig. 10a). Moreover, in the rain cases (Fig. 11a) the maximum jet speed is located at a higher level and appears widely around a height of $1-2 \mathrm{~km}$ in the nighttime, while that in the non-rain cases appears in the narrow layer around a height of $1 \mathrm{~km}$ in the nighttime. However, the double peak structure is not clear in these profiles. This could be because the averaging of profiles having two different peak heights causes the reduction of wind speed in the mean profile at the lower level when the wind speed of the lower peak is weaker than that of the higher one. In the non-rain cases (Fig. 11b), the jet structure of the mean wind becomes unclear be- tween 12-14 JST, although both the rain and nonrain cases exhibit an upward trend in the height of the LLJ in the afternoon. During this time, as shown in later analyses, the convective boundary layer (CBL) is mostly well mixed resulting in a weaker jet profile, in which the wind shear below and above the wind maximum is smaller compared with jet profiles in the nighttime. Moreover, the time of this extension varies from day to day, dependently on the evolution of the CBL. The averaging of those weakened jet profiles leads to the unclear jet structure between 1214 JST. After 14 JST, the CBL usually reaches its maximum height. The statistical examination of the LLJ occurrence indicates that the LLJ is more concentrated around a $2-\mathrm{km}$ height compared to previous times. Therefore, the jet structure has a peak in the mean wind profiles around this height after 14 JST. The upward trend results in the minor peak of frequency distributions at the higher level in the non-rain cases (Fig. 9c). On the other hand, in the rain cases the second peak is more pronounced and clearly separated from the first peak (Fig. 9b). Evidently, higher LLJs are more closely linked to rainfall events as suggested by Chen et al. 2005\}. The lower peak in their study was indicated as a barrier jet mainly due to the blocking effect of Taiwan mountain ranges. In our study, the lower peak could be brought from the selection of rainy days regardless of rainfall duration that leads to the appearance of LLJs in the boundary layer similar in the non-rain cases. (a)
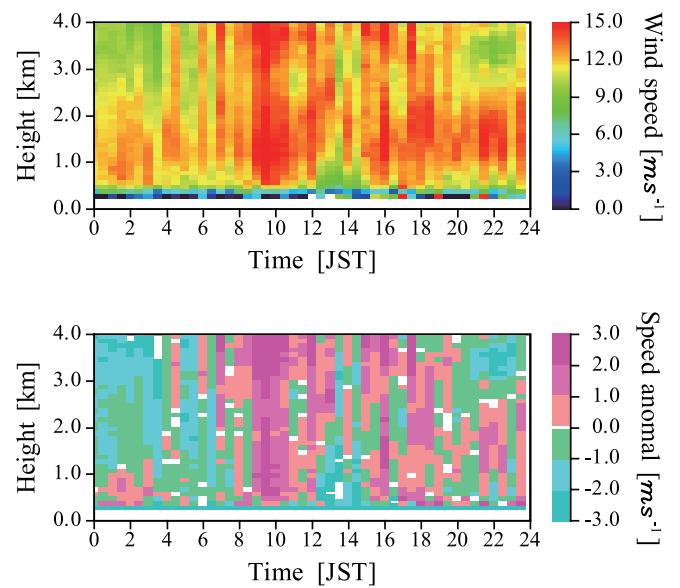

(b)
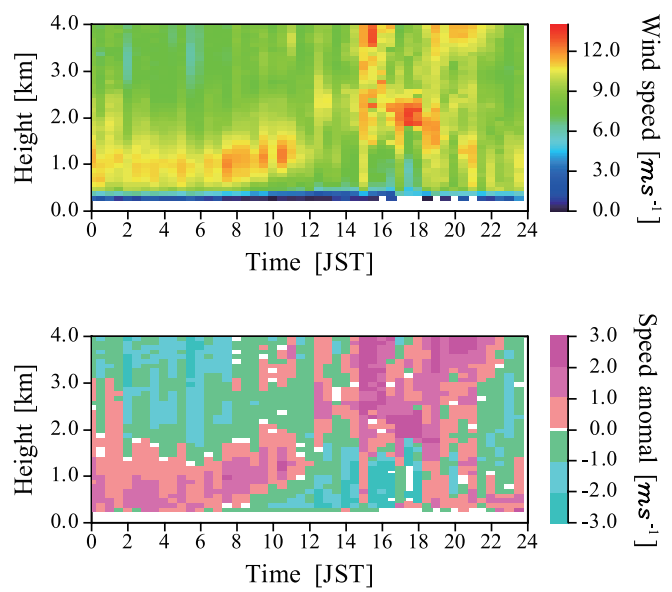

Fig. 11. Diurnal variations of the mean wind profiles as composited from LLJ soundings in the (a) rain cases and (b) non-rain cases from three months of the 3-year record. 
However, the blocking effect could also cause the lower peak over Okinawa Island. This effect is discussed in the next section.

The cause for the LLJ diurnal variation is investigated from the $\mathrm{ABL}$ structure and development. In 2005, under the Lower Atmospheric and Precipitation Study (LAPS) project an intensive observation period (IOP) was carried out on 12 continuous days from 29 June to 10 July for observing the ABL structure and development over Okinawa island. The $400-\mathrm{MHz}$ WPR, a polarimetric Doppler radar (COBRA), GPS radiosonde upper-air soundings, automatic weather stations, and a VIDEO camera were used in this experiment. We use upper-air sounding data obtained every 2 or 3 hours during a day in the IOP to examine the evolution of the ABL over the site. An example of a LLJ day (06 July), belonging to the postBaiu and the non-rain cases, is presented in Fig. 12; (a) the time-height cross section of horizontal wind; (b) profiles of specific humidity and virtual potential temperature. The upper-air sounding observations confirm the jet structure of the boundary layer wind. In the nighttime and early morn- ing, strong winds are found around a height of 1 $\mathrm{km}$ (Fig. 12a), where profiles of virtual potential temperature show a stable layer and the vertical gradient of specific humidity is very large. In the morning and afternoon a CBL with an almost constant virtual potential temperature develops upward and results in the weaker and more uniform wind in this CBL (Fig. 12b). The upward shift of the height with the wind speed maximum, from about $1.0 \mathrm{~km}$ by $08-10$ JST to $1.5-2.0 \mathrm{~km}$ after 12 JST, obviously follows the CBL height that is defined by the middle height in the stable layer found at the top of the CBL (Stull 1988). The phase shift of LLJ heights with time had been described by Krishna (1968), based on simple model simulation and observations. Moreover, he also noted that this shift depends on latitude. At latitudes north of $30^{\circ} \mathrm{N}$ the downward shift occurs in the nighttime and early morning, while at latitudes south of $30^{\circ} \mathrm{N}$ the upward shift occurs in the late morning. The upward shift of LLJ heights in our study is in agreement with the case at latitudes south of $30^{\circ} \mathrm{N}$. However, Krishna's result seems to be explained by Blackadar's

(a)

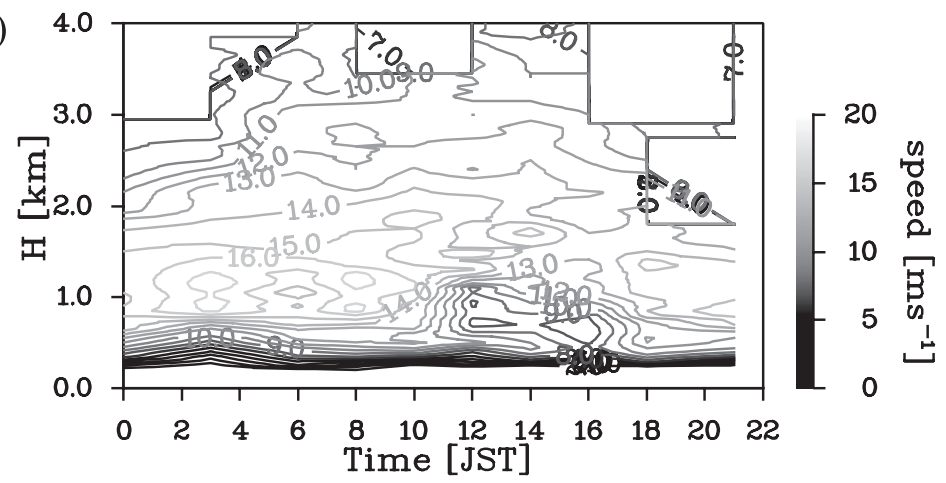

(b)

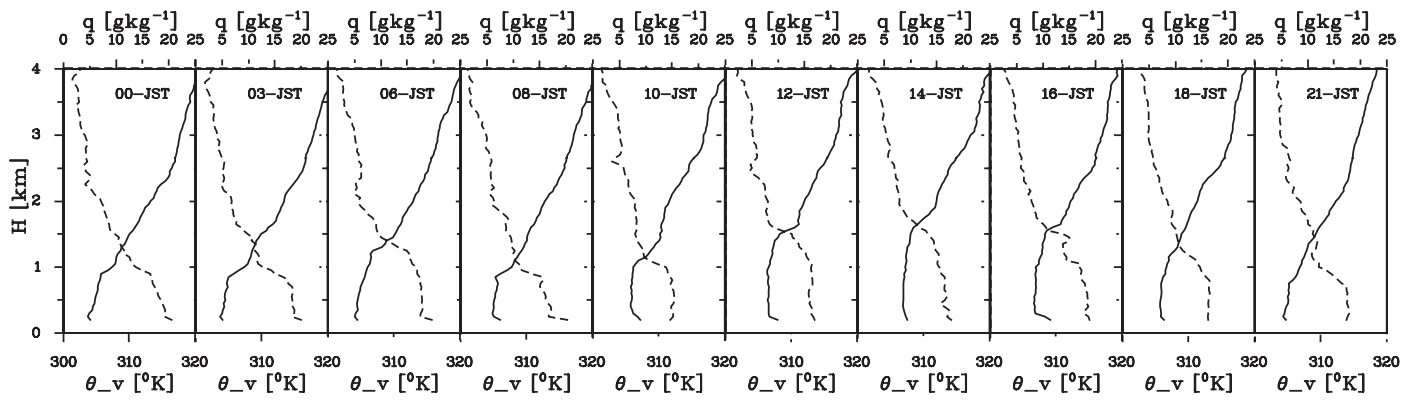

Fig. 12. Diurnal variations of the (a) wind and (b) virtual potential temperature (solid) and specific humidity (dash) observed by upper-air sounding on 2005 July 06. 
mechanism. Since Okinawa Island is small, it is doubtful that Blackadar's mechanism works, but the turbulence stress may still take effect. Further discussion on the boundary layer effect is made in the next section.

\section{Discussion}

Different dynamic processes have been proposed to explain the formation, intensification, and variation of LLJs, particularly for those over East Asia. As described in the previous section, although the stronger and weaker LLJs are confined to different heights and attributed to different atmospheric conditions, both of them undergo a diurnal variation with an enhanced nocturnal phase. It is suggested that under various synoptic conditions this diurnal variation of LLJs may also be influenced by local effects. Those could be the development of the boundary layer and inertial oscillation, land-sea breeze, and topography. The following discussion is focused on those potential influences.

Okinawa Island is oriented in a southwest to northeast direction, and it is approximately 100 $\mathrm{km}$ in length and about $15-25 \mathrm{~km}$ in width. The average elevation of the hilly terrain is $200-300$ $\mathrm{m}$ above MSL (Fig. 1). The highest ridges run parallel to the axis of the island. During the Baiu subperiod, synoptic southwesterly winds generally flow along the island. In contrast to the high central mountain range over Taiwan where the LLJ can form partly due to the blocking effect with a low Froude number (Fr) (Chen et al. 2005), the ambient flow usually goes over Okinawa Island according to predominantly high $\mathrm{Fr}$ values estimated from upper-air sounding data in the mentioned 2005 IOP (not shown). High Fr is calculated from the low terrain height and relatively weak stability (Brunt-Väisäla frequency in an order of $10^{-2} \mathrm{~s}^{-1}$ ) of the average strong southwest flow from the tropical ocean into Okinawa Island.

Next, the land-sea breeze is examined. Surface winds observed by weather stations showed that the southwest wind direction was generally maintained through the day (not shown). It indicates that the land-sea breeze cannot play an important role in generating the diurnal variation of LLJs.

The investigation on the boundary layer evolution over Okinawa Island, presented in the previous section, indicated the development of the CBL with uniform potential temperature in the daytime. Moreover, the effect of the $\mathrm{CBL}$ (a)

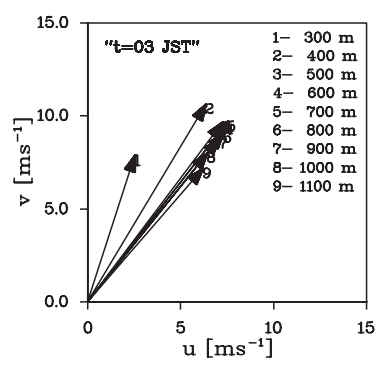

(b)

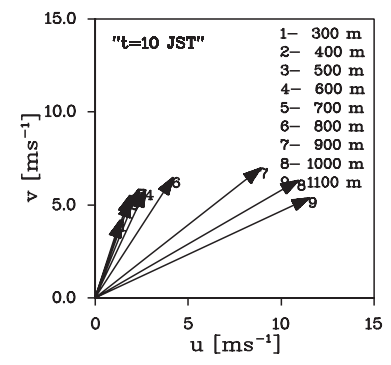

Fig. 13. Variation of the wind with height observed by upper-air sounding at (a) 03 JST and (b) 10 JST on 06 July 2005.

development on the wind structure in the CBL is examined using the Ekman spiral plot, shown in Fig. 13. Obviously, in the daytime (Fig. 13b) winds veer smoothly with height within the CBL and gradually become strongest at the top of the CBL. In the nighttime (Fig. 13a), winds also veer and gradually become strong with height but at a smaller angle, and attain the maximum speed around the height of the nocturnal strong stable layer. Above the stable layer winds become weaker. It is evident that the diurnal variation of vertical eddy viscosity in the ABL has a considerable role in regulating the diurnal variation of LLJs, which leads to the occurrence of the LLJ maximum in the nighttime because of the reduction of vertical mixing after sunset.

Nocturnal wind maxima, which are a common feature in the lower troposphere, are found in many regions over the world, particularly in the Great Plains of the United State. A similar LLJ is observed over the Kanto Plain in Japan. By observational studies, Harada (1981) reported that although the diurnal variation of the jet wind speed became stronger when the jet passed over the land, a nocturnal LLJ with the diurnal variation occurred at the coast and islands south of the Kanto Plain. Kimura and Arakawa (1983), from their numerical experiment on the Kanto LLJ, indicated that the primary factor of the jet formation is the mechanical effect of the mountains; the thermal effect enhances the LLJ and produces a diurnal variation. They also mentioned that the turbulence stress also plays an important role in generating the diurnal variation of the LLJ. Far away from the Kanto Plain, Okinawa is free from the central mountain effects of main is- 
lands of Japan and its area scale is about 10 times smaller than that of the Kanto Plain, although the jet flow there also experiences a diurnal variation with a nocturnal preference. To examine the LLJ in geographical conditions similar to Okinawa Island, we expand our analysis to other islands surrounding Okinawa Island by using data from the JMA WPR network. Three surrounding available WPR stations are Naze at $28.38^{\circ} \mathrm{N}, 129.5^{\circ} \mathrm{E}$ with an altitude of 3-m above MSL, Yonaguni at 24.47 ${ }^{\circ} \mathrm{N}, 123.01^{\circ} \mathrm{E}$ with a 30 -m altitude, and Minamidaitojima at $25.83^{\circ} \mathrm{N}, 131.23^{\circ} \mathrm{E}$ with a $16-\mathrm{m}$ altitude (Fig. 1). Horizontal wind data from the JMA WPR network are available at 10-min intervals and their vertical resolution is $300 \mathrm{~m}$. The similar procedure for detecting the LLJs is applied to the same 12 months data of May, June, July of 2004-2006 years at those stations.

Figure 14 shows the diurnal variations of LLJ occurrence frequency at Naze, Yonaguni, and Minamidaitojima. A clear diurnal variation with higher frequency in the nighttime and morning hours is found at Naze (Fig. 14a), while a rather uniform distribution is displayed at Yonaguni and Minamidaitojima (Figs. 14b and 14c). The diurnal variation at Naze is similar to that at Okinawa (Fig. 6a). Figure 15 shows the diurnal variation of LLJ occurrence frequency in the rain and non- rain cases at Naze and Yonaguni, based on corresponding JMA's AMeDAS (Automated Meteorological Data Acquisition System) rainfall data. At Naze the non-rain cases exhibit the strongest diurnal variation with a preference peak in the early morning (Fig. 15b), while in the rain cases the frequency of LLJ occurrence slightly increases before midnight (Fig. 15a). At Yonaguni, both the rain and non-rain cases display the same pattern without clear nocturnal enhancements (Figs. $15 \mathrm{c}$ and $15 \mathrm{~d})$. In our study, the diurnal variation of the LLJ is noticeably present only at Ogimi and Naze sites, which are located in islands with the scale of approximately $1200 \mathrm{~km}^{2}$ and $710 \mathrm{~km}^{2}$, respectively. These islands are considerably bigger than Yonaguni and Minamidaitojima islands (29 $\mathrm{km}^{2}$ and $30 \mathrm{~km}^{2}$, respectively). This indicates that at islands where the ABL can develop well because of the island's surface heating in the daytime, the diurnal variation of LLJs is generated as a result of the turbulence stress. Like the Kanto Plain, where the local pressure gradient due to the thermal effect of mountains contributes to the diurnal variation (e.g., Harada 1981; Kimura and Arakawa 1983), the ABL effect has an important role in regulating the diurnal variation of the LLJ over the Okinawa region. A similar diurnal variation was observationally found in the Somali LLJ (a)

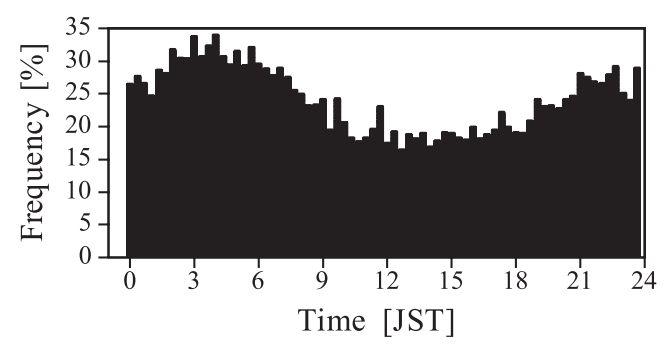

(b)

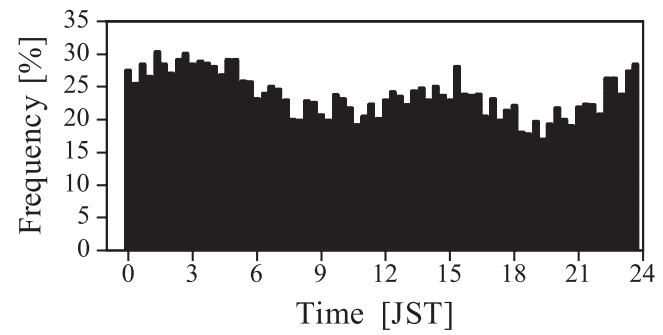

(c)

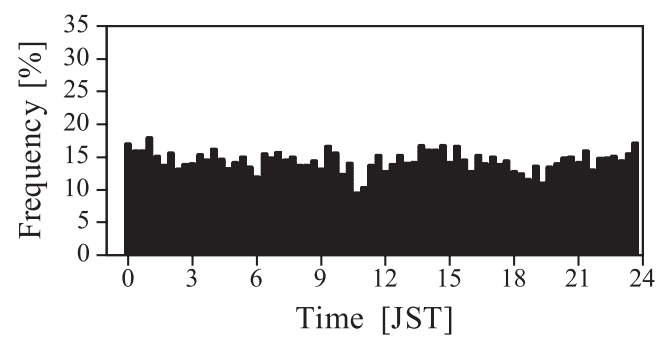

Fig. 14. Diurnal variations of the frequency of LLJ occurrence at (a) Naze, (b) Yonaguni, and (c) Minamidaitojima stations. 
(a)

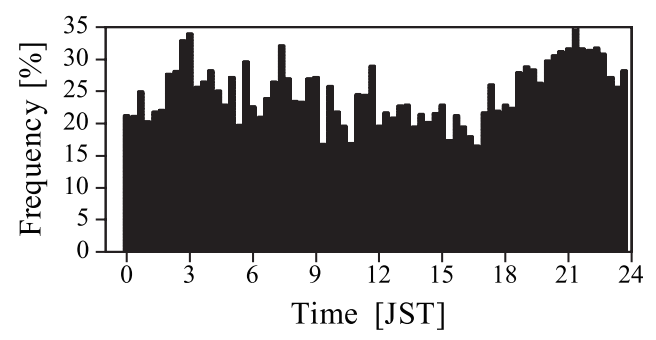

(c)

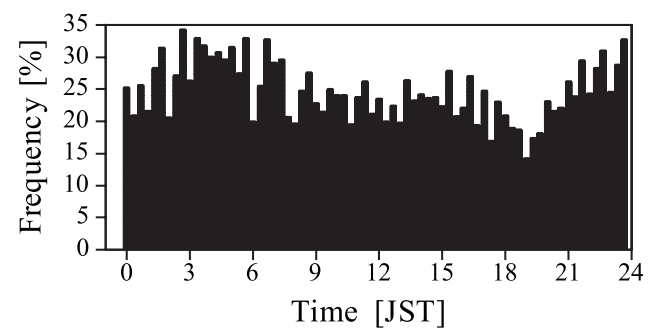

(b)

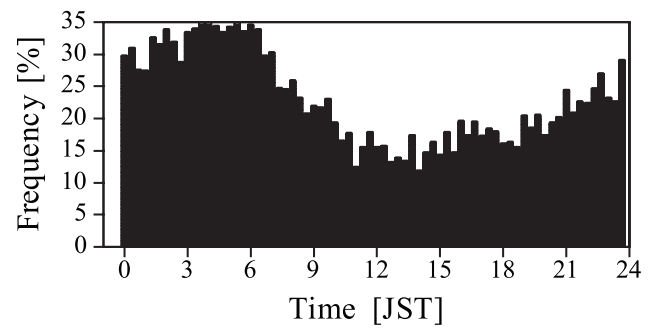

(d)

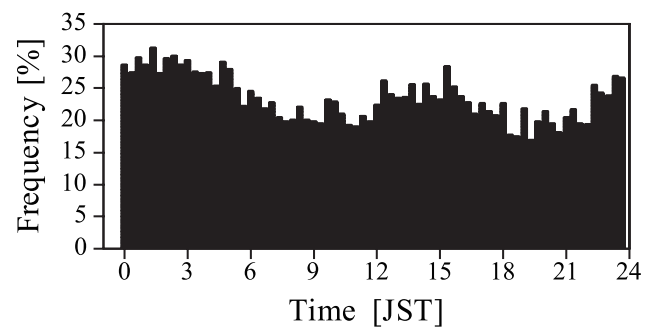

Fig. 15. Diurnal variations of the frequency of LLJ occurrence at Naze in the (a) rain cases and (b) nonrain cases, and at Minamidaitojima in the (c) rain cases and (d) non-rain cases.

at two sites over northeast Africa in the study of Ardanuy (1979). Following his interpretation the most important contribution to the diurnal variation of the Somali LLJ was the eddy transport of momentum by dry convection and turbulence in the daytime.

The double peak structure in the vertical distribution of the appearance frequency of the LLJ maximum height is discussed here. The clear upward extension of LLJ heights in the non-rain cases suggests that the minor second peak occurs as a result of boundary layer processes. In relation to this speculation, the diurnal variations of the LLJ occurrence frequency above and below a height of $1000 \mathrm{~m}$ are displayed in Fig. 16. In the non-rain cases, the diurnal variation below a $1-\mathrm{km}$ height has the enhanced frequency in the nighttime and early morning, and the lowest occurrence in the daytime (Fig. 16a), while the variation above a $1-\mathrm{km}$ height has the largest frequency in the morning (Fig. 16b). In the rain cases, the LLJ occurrence frequency below a $1-\mathrm{km}$ height exhibits a diurnal variation similar to that in the non-rain cases but with smaller amplitude, and larger frequency is found in the nighttime than in the morning (Fig. 16c). The frequency above a 1-km height in the rain cases (Fig. 16d) shows no clear diurnal variation, and has higher values between 08-15 JST and before midnight. In the non-rain cases the higher LLJs (above a $1-\mathrm{km}$ height) occur most frequently in the morning, which is brought from an upward extension of LLJ heights.

On the other hand, in the rain cases LLJs often occur above a 1-km height in the nighttime (see Fig. 16d). This also contributes to the generation of the second peak above a $1-\mathrm{km}$ height in the rain cases, which suggests the occurrence of LLJs at different levels due to different mechanisms. To clarify the contribution, two typical rainy cases with heavy and light rainfall are selected to examine their different LLJ structure over Ogimi (Fig. 17). The heavy rain on June 15, 2005 (Fig. 17d) is somewhat related to the stronger LLJ, which occurred at around a height of 1-2 km between 00-05 JST and 3-4 km in the afternoon (Fig. 17b). In this case, wind speed in the lower troposphere decreases sharply with the occurrence of very intense precipitation between 19-24 JST. However, in other cases (not shown), the strong wind speed in the lower troposphere and intense precipitation occur simultaneously at the station. In the investigation of enhancement processes of the LLJ with a simulation of the torrential rainband over southern Kyusyu, Kato (1998) suggested that the strong LLJ appears dependent- 
(a)

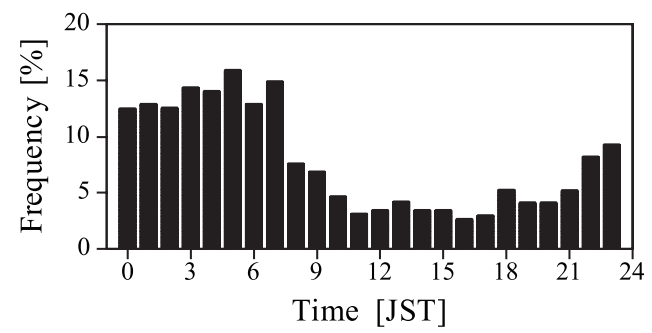

(c)

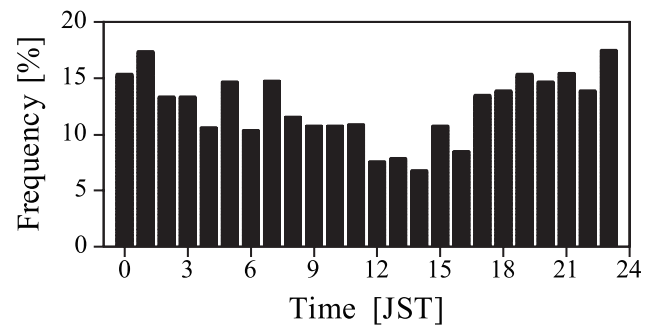

(b)

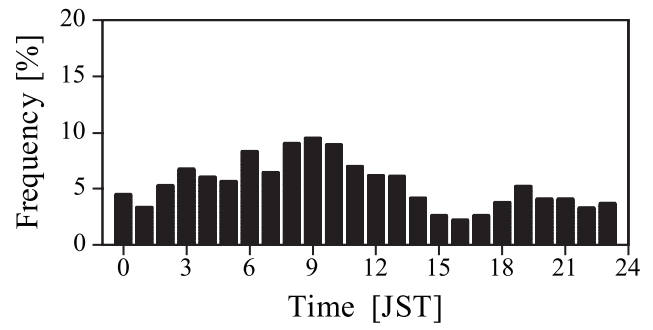

(d)

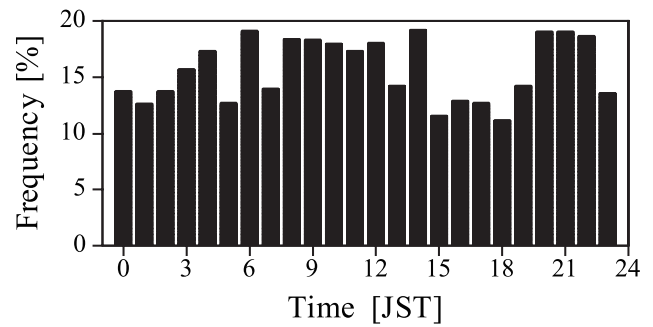

Fig. 16. Variation of LLJ frequencies occurring (a) below and (b) above a height of $1 \mathrm{~km}$ for the nonrain cases, and (c) below and (d) above a height of $1 \mathrm{~km}$ for the rain cases.

(a)

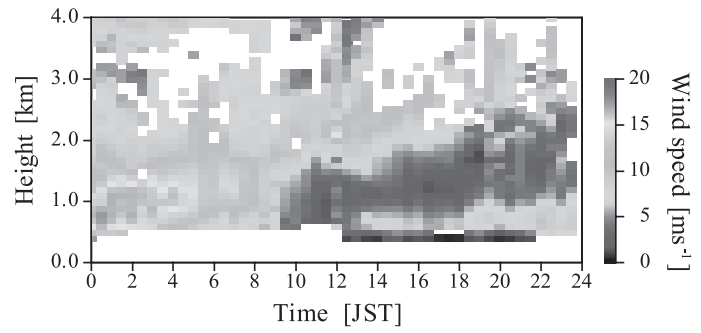

(c)

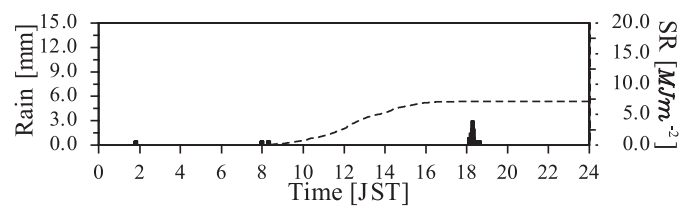

(b)

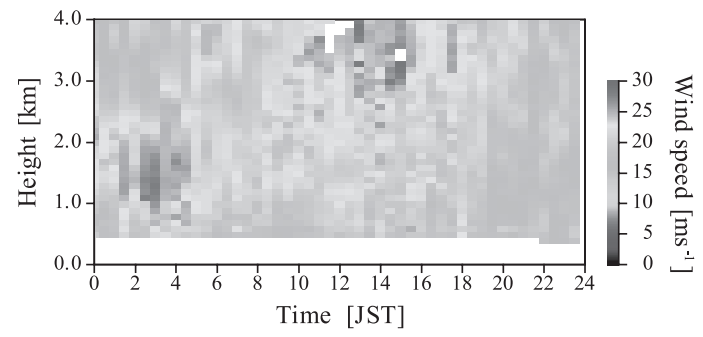

(d)

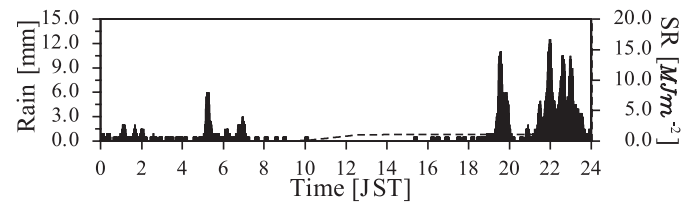

Fig. 17. Diurnal variations of wind speed observed by the Ogimi WPR on (a) 15 June 2006 and (b) 15 June 2005 and those of surface 10-min accumulated rainfall amount (shaded) and accumulated solar radiation (dash line) observed by the automatic weather station on (c) 15 June 2006 and (d) 15 June 2005.

ly on rainfall areas, which could be located at the north or south of the LLJ core. In contrast, the weaker LLJ occurred below a height of $1.5 \mathrm{~km}$ in the nighttime (00-04 JST and 22-24 JST), associated with light rainfall on June 15, 2006 (Fig. 17a and Fig. 17c). Compared to the heavy rainy day, the light and short rainy day had stronger solar radiation (dash line in Fig. 17c and Fig. 17d) in the daytime, which may lead to the development of the CBL in the daytime and the decoupling of the low-level flow from the accelerated flow aloft at the top of the nocturnal stable layer after sun- 
(a)

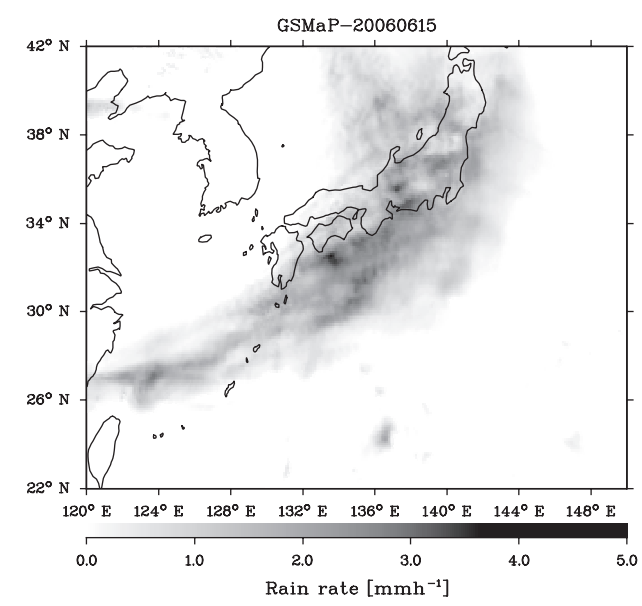

(b)

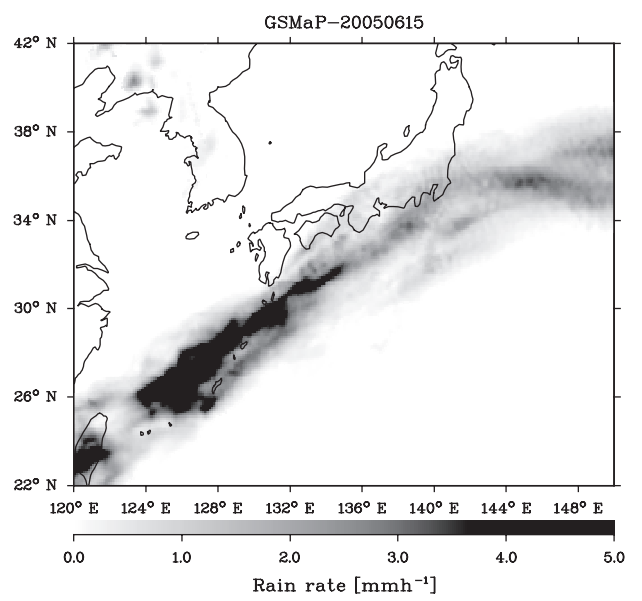

Fig. 18. Distributions of estimated rainrate, depicted from GSMaP data on (a) 15 June 2006 and (b) 15 June 2005.

set. Figure 18 shows the rainfall distribution on June 15, 2006 and 15, 2005, depicted from GSMaP "MVK" (Global Satellite Mapping of Precipitation - (Okamoto et al. 2005)) data. The main rainfall system associated with the Baiu front is weak and located north of Okinawa on June 15, 2006 (light rainy day), while a stronger rain belt is overhead Okinawa on June 15, 2005 (heavy rainy day). This suggests that even during the rainy period the occurrence and diurnal variation of LLJs are more related to boundary layer processes, while the higher and stronger LLJs also associate with the precipitation system and the amplitude of the diurnal variation is relatively small.

In the rain cases over the Baiu frontal zone, as pointed by Kato (1998) and Kato (2006) there could be two jets occurring at around $1 \mathrm{~km}$ and 3-4 km levels. The above example of the heavy rain day also displays the occurrence of LLJs at these different levels. Our presented analysis is restricted below a $3 \mathrm{~km}$ level, therefore the higher branch LLJ at a 3-4 km level has not been included. To examine the statistical occurrence of this "Baiu jet" as called by Kato (2006) in relation with precipitation, we extend the analysis up to a $4-\mathrm{km}$ height. Figure 19 displays the vertical distribution of LLJ frequency up to a $4-\mathrm{km}$ height for the rain cases and non-rain cases. Besides two peaks at lower layers, another peak is found around a height of 3-4 km in the rain cases (Fig. 19a), while in the non-rain cases such a peak is not pronounced and no clear gap is found between layers above and below a 1-km height (Fig. 19b).

From the above-mentioned speculation on the occurrence and diurnal variation of LLJs over Okinawa Island, the lowest LLJ is related to the $\mathrm{ABL}$ processes and is characterized by a strong diurnal variation, and the second peak of LLJ occurrence frequency may be the lower branch of "Baiu jet" related to convective activities over the Baiu frontal zone (Kato 1998). Therefore, the diurnal variation corresponding to the second peak could be more influenced by convective activities. However, all discussion mentioned above regarding mechanisms of the diurnal features of LLJs is based on statistical analyses of observational data. Without numerical models it is difficult to rule out the predominance of the forcing, which affects the LLJ behavior in individual cases.

\section{Summary and conclusions}

In the present study, $400-\mathrm{MHz}$ wind profiler observations at Ogimi over Okinawa Island for three months (May-July) of three years between 2004 and 2006 have been used for the first time to investigate the climatological characteristics, structure and diurnal variation of the southerly LLJs in the Baiu season. The quality of available data was examined through its missing rate to ensure its adequacy for climatological statistics. The data captured during the studied period had a lower 
(a)

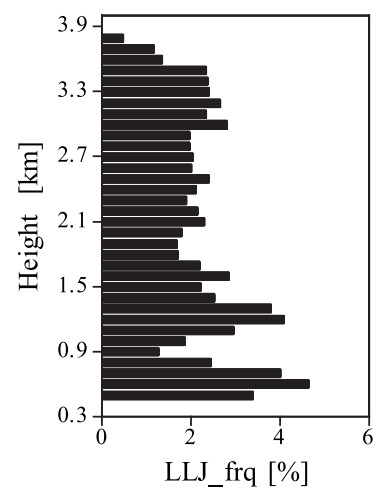

(b)

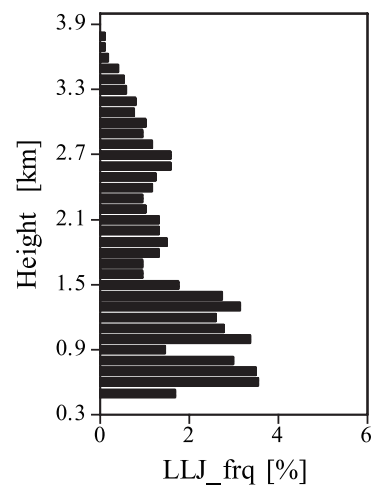

Fig. 19. Vertical distributions of the frequency of LLJ occurrence up to a height of $4 \mathrm{~km}$ for the (a) rain cases and (b) non-rain cases from three months of the 3-year record.

missing rate of around $20 \%$ compared to $40 \%$ in the winter season. The distribution of the 10-day occurrence frequency of southerly LLJs showed the maximum rate of $30 \%$ in the period of June 11-20, when convective activities were usually intense over the Baiu frontal zone. In comparison with the post-Baiu season, the stronger LLJs occurred more frequently, especially in June, when heavy precipitation is more often observed. Additionally, the direction of LLJ changed from southwesterly in the Baiu season to southerly in the post-Baiu season.

The separation of the three month period into the rain and non-rain cases was made to examine the relation of precipitation to the LLJs characteristics. A double peak distribution of LLJ heights was revealed in the vertical distribution of their appearance frequency. The more pronounced higher peak in the rain cases suggests that some higher LLJs link to rainfall events similarly to the results of Chen et al. (2005). The association of higher and stronger jets with precipitation is also examined in the mean wind vertical structure constructed from LLJ profiles separately for the rain and non-rain cases. In the rain cases, the mean maximum wind is stronger, and the LLJ heights are found about $1 \mathrm{~km}$ higher in comparison with that in the non-rain cases. Moreover, it was found that the LLJ possesses a diurnal variation with an enhancement of occurrence frequency in the nighttime and early morning. During $12-14$ JST the jet structure becomes unclear in the non-rain cases, but an upward trend of LLJ heights in the morning is analyzed in both the cases.

Additional results from data of the JMA WPR network for three stations surrounding Okinawa Island show that a similar diurnal variation of the LLJ was also analyzed at Naze, which is located in an island with land area comparable to Okinawa Island. In very small islands such as Yonaguni and Minamidaitojima Islands, since the diurnal variation of the turbulence stress is expected to be much weaker, a clear diurnal variation of LLJ occurrence frequency with the nocturnal maximum is not analyzed. Moreover, the LLJ diurnal variation is enhanced particularly in the non-rain cases at both Ogimi and Naze. Harada (1981) showed in the observational studies of LLJs over the Kanto Plain that the diurnal variation also appeared at islands far south of the Kanto Plain. It is anticipated from our discussion that the diurnal variation of LLJs over Okinawa regions is largely controlled by the ABL processes. This could differ from the LLJ over the Kanto Plain, where influences by both mountain effects and turbulence stress are important (e.g., Harada 1981; Kimura and Arakawa 1983).

Our analysis was mainly based on local observations, and the relationship between the LLJ formation and the synoptic condition is beyond the scope of this investigation. Our result shows that the LLJ is related to both precipitation activities, associated with synoptic disturbances, and the ABL processes. The separate examination on the effects of precipitation and ABL processes is still incomplete and open in our future study. Together with this examination, further studies should include: (1) the diurnal variation of the high altitude (about 3-4 km) LLJ, (2) the relation between locations of LLJs and the precipitation systems using GSMaP data, (3) the similar analysis for other seasons, and (4) the analysis using fine scale numerical model results.

\section{Acknowledgments}

This work was supported by the Core Research for Evolutional Science and Technology of Japan Science and Technology Agency. The authors wish to express their thanks to members of the Okinawa Subtropical Remote Sensing Center, who conducted observations on Okinawa Island. JMA WPR data were provided by the JMA. The authors wish to express their thanks to Dr. 
Teruyuki Kato of the Meteorological Research Institute, the JMA and two anonymous reviewers for critical, helpful suggestions and comments, which led to major improvements of the original manuscript. We are grateful to all members of the Satellite Meteorology Laboratory of Hydrospheric Atmospheric Research Center at Nagoya University.

\section{References}

Adachi, T., Y. Masuda, and S. Fujii, 2001: Development of a $400 \mathrm{MHz}$-band wind profiler radar in Okinawa. Proc. Third Inter. Symp. on Asian Monsoon System (ISAM3), 309-313.

Akiyama, T., 1973a: Ageostrophic low-level jet stream in the Baiu season associated with heavy rainfalls over the sea area. J. Meteor. Soc. Japan, 51, 205-208.

Akiyama, T., 1973b: Frequent occurence of heavy rainfall along the north side to the low-level jet stream in the Baiu season. Pap. Meteor. Geophys., 24, 379-388.

Akiyama, T., 1973c: The large-scale aspects of the characteristic features of the Baiu front. Pap. Meteor. Geophys., 24, 157-188.

Angevine, W.M., S.K. Avery, and G.L. Kok, 1993: Virtual heat flux measurements from a boundary layer profiler-RASS compared to aircraft measurements. J. Appl. Meteor., 32, 1901-1907.

Ardanuy, P., 1979: On the observed diurnal oscillation of the Somali jet. Mon. Wea. Rev., 107, 16941700.

Arritt, R.W., T.D. Rink, M. Segal, D.P. Todey, and C.A. Clark, 1997: The Great Plains low-level jet during the warm season of 1993. Mon. Wea. Rev., 125, 2176-2192.

Banta, R.M., R.K. Newsom, J.K. Lundquist, Y.L. Pichugina, R.L. Coulter, and L. Mahrt, 2002: Nocturnal low-level jet characteristics over Kansas during CASES-99. Bound.-Layer Meteor., 105, 221-252.

Blackadar, A.K., 1957: Boundary layer wind maxima and their significance for the growth of nocurnal inversion. Bull. Amer. Meteor. Soc., 38, 283290.

Bonner, W.D., 1968: Climatology of the low level jet. Mon. Wea. Rev., 96, 833-850.

Chen, G.T. and C.-C. Yu, 1988: Study of low-level jet and extremely heavy rainfall over northern Taiwan in the Mei-Yu season. Mon. Wea. Rev., 116, 884-891.

Chen, Y., X.-A. Chen, and Y.-X. Zhang, 1994: A diagnostic study of the low-level jet during TAMEX IOP 5. Mon. Wea. Rev., 122, 2257-2284.

Chen, G.T., C. Wang, and D.T.-W. Lin, 2005: Charac- teristics of low-level jets over northern Taiwan in Mei-Yu season and their relationship to heavy rain events. Mon. Wea. Rev., 133, 20-43.

Chou, L.C., C.-P. Chang, and R.T. Williams, 1990: A numerical simulation of the Mei-Yu front and the associated low level jet. Mon. Wea. Rev., $118,1408-1428$.

Findlater, J., 1981: An experiment in monitoring crossequatorial airflow at low level over Kenya and rainfall of western India during the northern summers. S.J. Lighthill, and R.P. Pearce, Eds., Monsoon Dynamics, Cambridge Univer. Press, 309-319.

Harada, A., 1981: An analytical study of nocturnal low-level jet over the Kanto Plains, Japan. Pap. Meteor. Geophys., 32, 233-245.

Holton, J.R., 1967: The diurnal boundary layer wind oscillation above sloping terrain. Tellus, 19, 199205.

Kato, T., 1998: Numerical simulation of the bandshaped torrential rain observed over southern Kyushu, Japan on 1 August 1993. J. Meteor. Soc. Japan, 76, 97-128.

Kato, T., 2006: Structure of the band-shaped precipitation system inducing the heavy rainfall observed over northern Kyushu, Japan on 29 June 1999. J. Meteor. Soc. Japan, 84, 129-153.

Kimura, F. and S. Arakawa, 1983: A numerical experiment on the nocturnal low level jet over the Kanto Plain. J. Meteor. Soc. Japan, 61, 848-861.

Krishna, K., 1968: A numerical study of the diurnal variation of meteorological parameters in the planetary boundary layer. Mon. Wea. Rev., 96, 269-276.

Mahrt, L., 1981: The early evening boundary layer transition. Quart. J. Roy. Meteor. Soc., 107, 329343.

Matsumoto, S., 1972: Unbalanced low-level jet and solenoidal circulation associated with heavy rainfalls. J. Meteor. Soc. Japan, 50, 194-203.

Matsumoto, S., 1973: Lower tropospheric wind and precipitation activity. J. Meteor. Soc. Japan, 51, 101-107.

Matsumoto, S., K. Ninomiya, and S. Yoshizumi, 1971: Characteristic features of Baiu front associated with heavy rainfall. J. Meteor. Soc. Japan, 49, 267-280.

Merritt, D.A., 1995: A statistical averaging method for wind profiler Doppler spectra. J. Atmos. Oceanic Technol., 12, 985-995.

Mitchell, M.K., R.W. Arritt, and K. Labas, 1995: An hourly climatology of the summertime Great Plains low-level jet using wind profiler observation. Wea. Forecasting, 10, 576-591.

Nagata, M. and Y. Ogura, 1991: A modeling case study of interaction between heavy precipitation and a low-level jet over Japan in the Baiu season. 
Mon. Wea. Rev., 119, 1309-1336.

Ninomiya, K. and T. Akiyama, 1992: Multi-scale features of Baiu, the summer monsoon over Japan and east Asia. J. Meteor. Soc. Japan, 70, 337365.

Ninomiya, K. and T. Murakami, 1987: The early summer rainy season (Baiu) over Japan. C.-P. Chang, and T.N. Krishnamurti, Eds., Monsoon Meteorology, Oxford Univ. Press, 93-121.
Okamoto, K., T. Iguchi, N. Takahashi, K. Iwanami, and T. Ushio, 2005: The Global Satellite Mapping of Precipitation (GSMaP) project. 25th IGARSS Proceedings, 3414-3416.

Stensrud, D.J., 1996: Importance of low level jets to climate: A review. J. Climate, 9, 1698-1711.

Stull, R.B., 1988: An Introduction to Boundary Layer Meteogology. Kluwer Academic Publisher, 670 pp. 